\title{
Effect of Fineness on Mechanical Properties of Cementitious Material Made from Magnesia Slag
}

\author{
Dan Cheng ${ }^{1}$, Jianxun $\mathrm{Ma}^{1, \mathrm{a}}$, Yilei Zhang ${ }^{1}$, Xuhui Chen ${ }^{2}$ and Wenxiao $\mathrm{Li}^{1}$ \\ ${ }^{1}$ School of Human Settlements and Civil Engineering, Xi'an Jiaotong University, Xian, China \\ ${ }^{2}$ Xi'an company, China Overseas Land \& Investment Ltd, Xian, China
}

\begin{abstract}
Magnesium slag is a kind of solid waste discharged by magnesium alloy related industries in the process of producing magnesium products or their alloys. Its composition is similar to Portland cement clinker, so it has great potential to be used as a new cementing material. In this paper, magnesium slag cementitious material specimens with different fineness were made by imitating the actual production environment. The flexural strength and compressive strength of specimens with different curing ages were tested, and the influence of fineness on them was analyzed. The results show that the fineness has a significant effect on the mechanical properties of pure magnesium slag cementitious materials. Its effect on the early strength is greater than that on the later strength. But the flexural strength and compressive strength will not always increase with the increase of fineness. There is a reasonable range of fineness.
\end{abstract}

\section{Introduction}

With the development of industrial technology and the increase of energy demand, magnesium alloys have been widely used in automotive industry, aerospace industry and electrical communication industry. It is second only to the application of aluminum alloy. Magnesium slag is a kind of solid waste discharged by magnesium alloy related industries in the process of producing magnesium products or their alloys. Magnesium ore is reduced to coarse magnesium through relevant industrial chemical reaction. The remaining waste is magnesium slag ${ }^{[1]}$. Magnesium slag has strong hygroscopicity, easy to make soil salinization, resulting in soil hardening. At the same time, the powder magnesium slag particles are easy to mix in the air, causing dust pollution.

China is rich in available magnesium mineral resources, and the magnesium industry is developing rapidly. However, with the rapid development of magnesium industry, how to efficiently and reasonably recycle magnesium slag has become an urgent problem.

Fineness is an index to characterize the thickness of a substance. ${ }^{[2]}$ For magnesium slag, the fineness of magnesium slag is the index of grinding degree or dispersion degree of magnesium slag. The chemical composition of magnesium slag is very similar to Portland cement, so for the cementitious materials made of these two materials, the influence factors on their mechanical properties should be the same ${ }^{[3]}$. Studies at home and abroad show that the fineness of cement has an important influence on the performance of concrete. Therefore, the effect of fineness on the mechanical properties of magnesium slag cementitious materials can not be ignored.

\section{Test}

\subsection{Test raw materials}

Magnesium slag, tap water, glass (grinding aid) and 100\% pure magnesium slag were selected as test materials. Considering that the change of test materials and methods will cause the change of test results, the magnesium slag used in the test is the same batch of magnesium slag produced by the same company. The magnesium slag is white powder. Its main chemical composition is $\mathrm{SiO}_{2}$, $\mathrm{CaO}$ and $\mathrm{Fe}_{2} \mathrm{O}_{3}$. The specific chemical composition is shown in Table 1. The test water was clean tap water. The water cement ratio is 0.275 . There were only differences in particle size and age among different groups.

Table 1. Chemical composition of magnesium slag

\begin{tabular}{|c|c|c|c|c|c|}
\hline Component & $\mathrm{SiO}_{2}$ & $\mathrm{CaO}$ & $\mathrm{MgO}$ & $\mathrm{Al}_{2} \mathrm{O}_{3}$ & $\mathrm{Fe}_{2} \mathrm{O}_{3}$ \\
\hline $\begin{array}{c}\text { Content } \\
(\%)\end{array}$ & 21.89 & 60.07 & 3.86 & 3.56 & 8.14 \\
\hline
\end{tabular}

\subsection{Specimen size}

The raw materials used in this experiment are magnesium slag, fly ash and water. The properties of specimens are similar to those of cementitious materials. The test piece size, mixing and pouring method refer to "Test Method for Strength of Cement Mortar (ISO method)" GB/T

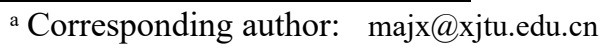


17671-1999. The specimen was a prism of $40 \mathrm{~mm} \times 40 \mathrm{~mm} \times 160 \mathrm{~mm}^{[4]}$

\subsection{Test scheme}

Three groups of pure magnesium slag cementitious materials with different fineness were prepared. Its fineness is 100 mesh, 150 mesh and 200 mesh respectively. The specific number of specimens is shown in Table 2. Under natural curing conditions, the specimens were cured for 3, 7, 14 and 28 days, respectively. Observe the curing results and measure the flexural and compressive strength. Record the failure of the specimen and analyze the mechanical test data.

Table 2. Summary of sample number of pure magnesium slag

\begin{tabular}{|c|c|c|c|c|}
\hline $\begin{array}{c}\text { Specimen } \\
\text { number }\end{array}$ & $\begin{array}{l}\text { Fineness } \\
\text { /mesh }\end{array}$ & $\begin{array}{c}\text { Curing } \\
\text { period } \\
\text { /day }\end{array}$ & $\begin{array}{c}\text { Magnesiu } \\
\mathrm{m} \text { slag /g }\end{array}$ & Water /g \\
\hline $1-1-1$ & \multirow{3}{*}{100} & 7 & \multirow{9}{*}{1350} & \multirow{9}{*}{$\begin{array}{l}371 . \\
3\end{array}$} \\
\hline $1-1-2$ & & 14 & & \\
\hline $1-1-3$ & & 28 & & \\
\hline $1-2-1$ & \multirow{3}{*}{150} & 7 & & \\
\hline $1-2-2$ & & 14 & & \\
\hline $1-2-3$ & & 28 & & \\
\hline $1-3-1$ & \multirow{3}{*}{200} & 7 & & \\
\hline $1-3-2$ & & 14 & & \\
\hline $1-3-3$ & & 28 & & \\
\hline
\end{tabular}

\subsection{Curing results}

In this test, all specimens were cured and formed, and no expansion crack occurred. Through the maintenance results of this test, it can be seen that the magnesium slag produced by a company after magnesium smelting has certain hydration activity. After the activation is stimulated by grinding, the pure magnesium slag cementitious material can be cured under natural conditions. It can be completely demoulded after 2 days of pre curing, and has a certain hardness. The curing of specimens is shown in Figure 1.

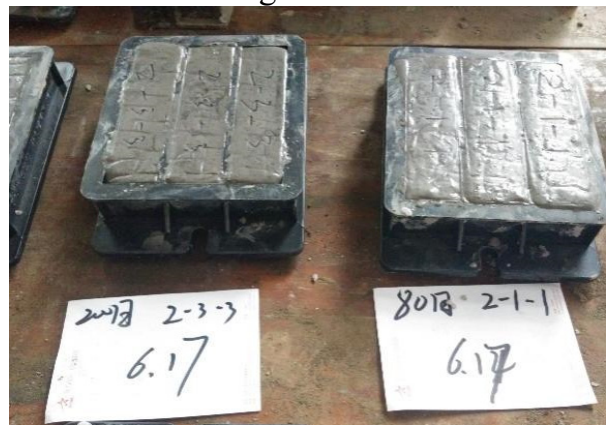

Figure 1. Production of pure magnesium slag sample

\section{5 mechanical property test}

\subsubsection{Flexural strength test}

(1) Bending test instrument

The bending part of the electro-hydraulic servo synchronous testing machine was used in the test. The loading mode is three-point loading. Hinged bearings are adopted with spacing of $100 \mathrm{~mm}$.

(2) Steps of bending test

When testing, wipe the specimen clean and measure the size. And check the appearance. The specimens that do not conform to the section characteristics are excluded. Then, the specimen is placed on the testing machine and loaded until the specimen breaks. Observe the cracks and record the test data.

(3) Bending test results

The bending test results are calculated according to Formula 1 . The results were accurate to $0.1 \mathrm{MPa}$.

$$
R_{b}=\frac{3 P l}{2 b h^{2}}
$$

In the formula: $R_{b}$ - flexural strength / MPa. $P$ - failure load / N. $l$ - bearing spacing / $\mathrm{mm}$. $b$ - section width / $\mathrm{mm}$. $h$ - section height / $\mathrm{mm}$.

The calculation of flexural strength test results can refer to "Cement Mortar Strength Test Method"[4]. The average value of the flexural strength of each group of specimens is taken as the flexural strength of the group of specimens. If the flexural strength of one specimen in a group exceeds $10 \%$ of the average flexural strength of the group, it shall be excluded as invalid data. If there is still more than $10 \%$ of the average value after excluding the invalid data, the group of data is invalid. Repeat the test.

\subsubsection{Compressive strength test}

(1) Compression test instrument

The compressive part of the same testing machine is selected for the test. The loading rate is $2.4 \mathrm{KN} / \mathrm{S}$.

(2) Compression test procedure

After cleaning the surface of the broken specimen in the bending test, place it on the compression machine. Load until the specimen is destroyed. Observe the section and record the test data.

(3) Compression test results

The compression test results are calculated according to formula $2 .{ }^{[4]}$ The results were accurate to $0.1 \mathrm{MPa}$.

$$
f_{c}=\frac{F_{c}}{A}
$$

In the formula: $f_{C^{-}}$- compressive strength $/ \mathrm{MPa} . F_{C^{-}}$ maximum load at failure $/ \mathrm{N}$. $A$ - area of compression part $/ \mathrm{mm} 2$, and its value is $40 \mathrm{~mm} \times 40 \mathrm{~mm}=1600 \mathrm{~m} \mathrm{~m}^{2}$.

The compressive strength test results can refer to "Cement Mortar Strength Test Method"[4]. The specific treatment method is the same as that of flexural strength. 


\section{Test result}

The specimens are pure magnesium slag cementitious materials under natural curing conditions. It is made of pure magnesium slag after grinding treatment, and has strong compressive strength after 28 days, which has a certain application value. In order to further analyze the effect of fineness on the mechanical properties of magnesium slag cementitious materials, the mechanical test records of the above pure magnesium slag specimens were summarized. The test results are shown in Table 2, Figure 2 and Figure 3. ${ }^{[5]}$

Table 3. Summary of flexural strength and compressive strength of specimens

\begin{tabular}{|c|c|c|c|}
\hline $\begin{array}{c}\text { Specimen } \\
\text { number }\end{array}$ & $\begin{array}{c}\text { Curing } \\
\text { period / } \\
\text { day }\end{array}$ & $\begin{array}{c}\text { Flexural } \\
\text { strength / } \\
\text { /MPa }\end{array}$ & $\begin{array}{c}\text { Compressive } \\
\text { strength / } \\
\text { /MPa }\end{array}$ \\
\hline $1-1-1$ & 7 & 2.3 & 14 \\
\hline $1-1-2$ & 14 & 3.1 & 17.4 \\
\hline $1-1-3$ & 28 & 3.4 & 17.2 \\
\hline $1-2-1$ & 7 & 3.2 & 16.4 \\
\hline $1-2-2$ & 14 & 3.5 & 20.6 \\
\hline $1-2-3$ & 28 & 3.6 & 21.3 \\
\hline $1-3-1$ & 7 & 2.7 & 15.7 \\
\hline $1-3-2$ & 14 & 3.3 & 18.4 \\
\hline $1-3-3$ & 28 & 3.5 & 19.1 \\
\hline
\end{tabular}

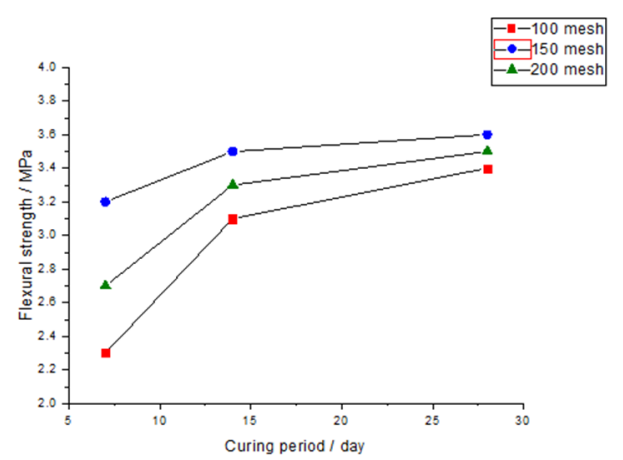

Figure 2. Summary of flexural strength

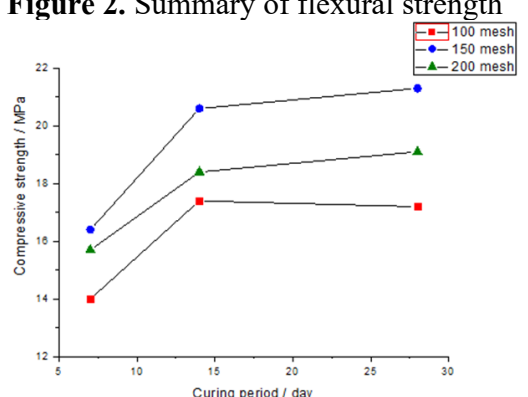

Figure 3. Summary of compressive strength

\subsection{Analysis of flexural strength}

It can be seen from Figure 2 that the flexural strength of specimens with different fineness groups is obviously different. The fineness has an effect on the flexural strength of pure magnesium slag.
It can be seen from the figure that the flexural strength of three kinds of fineness pure magnesium slag cementitious materials gradually increases with the increase of curing age. The trend of the curve is basically the same. With the increase of curing time, the rising trend slows down gradually. The flexural strength after 28 days is obviously higher than that after 3 days.

According to the three groups of data, among the three fineness of magnesium slag specimens, the strongest flexural strength is 150 mesh group, and the weakest is 100 mesh group. At the same time, it can be seen from the curve that the bending strength of the three kinds of fineness specimens is the biggest difference when they are cured for 7 days. At 28 days, the difference gradually decreased. Take the 150 mesh group with the largest intensity and the 100 mesh group with the smallest intensity as an example. At 7 days, the strength of 150 mesh is $39.1 \%$ higher than that of 100 mesh. $12.9 \%$ on 14 days. By 28 days, the intensity of 150 mesh was only $0.6 \%$ higher. ${ }^{[5]}$

\subsection{Analysis of compressive strength}

As shown in Figure 3, the broken line diagram of compressive strength of pure magnesium slag specimen is basically consistent with the bending curve. The compressive strength of 100 mesh, 150 mesh and 200 mesh specimens increased with the increase of curing age. The growth in the early stage is relatively large, and the change in the later stage is relatively stable. In the compressive strength, 150 mesh $>200$ mesh $>100$ mesh, consistent with the flexural strength.

\section{Conclusion}

By making pure magnesium slag specimens with different fineness, the influence of fineness on its mechanical properties under natural curing conditions was explored. Based on the analysis of the test results, the following conclusions are drawn.

(1) Under the condition of natural curing, the fineness has a significant effect on the mechanical properties of pure magnesium slag cementitious materials.

(2) There is an optimal fineness when exploring the influence of fineness. Through the test, it can be seen that the flexural strength and compressive strength of the specimen will not always increase with the increase of the fineness of the specimen, and there is a reasonable fineness range. For the magnesium slag selected in this test, the strength of 150 mesh magnesium slag cementitious material is better than that of 100 mesh and 200 mesh under the premise of keeping the water cement ratio unchanged.

(3) The influence of fineness on the early strength of magnesium slag cementitious material is greater than that on the later strength. ${ }^{[5]}$ 


\section{References}

1. Li Shanshan. Research progress of magnesium slag concrete $[\mathrm{J}]$. Sichuan cement, 2018.

2. Celik I B. The effects of particle size distribution and surface area upon cement strength development[J]. Powder Technology, 2009, 188(3): 272-276.

3. Ma Kunlin, he jionghuang, long Guangcheng, et al. Effect of steam curing temperature and its influence on thermal damage of cement-based materials $[\mathrm{J}]$. Materials guide, 2017, 31 (23): 171-176.

4. Tang Zhongning. Test method for strength of cement mortar (ISO method) [J]. CNBM, 1999.

5. Xuhui Chen. The effect of fineness on cementitious material made from magnesia Slag[D]. xian: Xi'an Jiaotong University, 2019. 